\title{
Preparation and Characterization of Hollow Glass Microspheres- Reinforced Poly (acrylonitrile-co-butadiene-co-styrene) Composites
}

\author{
Marina Panozzo Cunha ${ }^{a}$, Ana Maria Colon Grisa ${ }^{a}$, Jalma Klein ${ }^{a}$, Matheus Poletto ${ }^{a}$, \\ Rosmary Nichele Brandalise $e^{* *(1)}$ \\ ${ }^{a}$ Centro de Ciências Exatas e da Tecnologia, Universidade de Caxias do Sul, Rua Francisco Getúlio \\ Vargas, 1130, 95070-560, Caxias do Sul, RS, Brasil
}

Received: March 16, 2018; Revised: June 27, 2018; Accepted: August 16, 2018

\begin{abstract}
In this study, poly(acrylonitrile-co-butadiene-co-styrene)/hollow glass microspheres (ABS/HGM) composites were prepared by means of a twin-screw extruder. HGM were incorporated at different loadings of 2.5, 5.0, and $7.5 \mathrm{wt} . \%$ at the central extruder zone with different types of ABS. The morphological, physical, thermal, rheological and mechanical properties of ABS/HGM composites were investigated. Statistical analysis reveals that high impact ABS addition is significant for improving composites' impact strength. The results also indicated that addition of $5.0 \mathrm{wt} \%$ of HGM along with $5.0 \mathrm{wt} . \%$ of powdery ABS at the central extruder zone maintains the HGM integrity while powdery ABS contributes to better filler dispersion in the matrix resulting in light-weight composites having improved mechanical properties.
\end{abstract}

Keywords: Hollow glass microspheres, poly (acrylonitrile-co-butadiene-co-styrene), light-weight composites.

\section{Introduction}

In the last few years research communities worldwide have been making constant efforts for the development of industrially useful light-weight materials that also exhibit high mechanical performance ${ }^{1-4}$. As a result of recent developments in the field of polymer composites, some industries have engaged in the development of materials that offer greater flexibility in enhancing strength allied with weight reduction ${ }^{4}$. The materials, used in marine, aerospace and automotive applications need to exhibit low density associated with high strength, stiffness and high impact strength. In addition, environmental concerns are a challenge for the automotive industries to promote vehicle weight reduction without compromising their performance ${ }^{5-6}$. Therefore, hollow glass microspheres are normally used as reinforcing materials in a polymer matrix to produce light-weight composites with high mechanical properties ${ }^{3-4}$.

Hollow glass microspheres (HGM) consist of outer stiff glass spheres with gas inside and exhibit some desirable properties such as lightness, low thermal conductivity and low dielectric constant. In the average, HGM have diameter of 15 to $65 \mathrm{~mm}$ with a very thin wall of 0.5 to $1.5 \mathrm{~mm}$ and density between 0.12 and 0.60 g.cm ${ }^{-3} 1,2,7$. On the other hand, poly(acrylonitrile-co-butadiene-co-styrene)(ABS) is a widely used engineering thermoplastic owing to its desirable properties, such as good dimensional and thermal stability, processability, chemical resistance, mechanical properties and fair $\operatorname{cost}^{8}$. However, the low ABS rigidity may lead to drawbacks during usage. Therefore, reinforcing inorganic

"e-mail: rnbranda@ucs.br fillers such as HGM, calcium carbonate, talc, clay, etc, were used to improve ABS rigidity8.

Delogu and coworkers ${ }^{9}$ combined environmental and economic assessments to evaluate the usage of talc and HGM as reinforcing agents in polymer composites used as lightweight materials in automotive components. The authors observed that based both on environmental and economic assessments HGM-reinforced polymer composites are preferable to talc filler-reinforced composites. Liang ${ }^{10}$ studied the mechanical properties of three types of ABS composites reinforced with hollow glass beads of different sizes and size distributions using a twin-screw extruder. The authors observed that the composite mechanical properties increase at filler volume fraction of $5 \%$ and the effects of filler size and its distribution did not affect the mechanical properties evaluated. In our previous work ${ }^{11}$, ABS was reinforced with HGM to evaluate the effect of HGM addition at two different extruder feeding zones. The results showed that HGM at a maximum of $5.0 \mathrm{wt} . \%$ greatly improved the properties of the composites, including thermal stability as well as mechanical and rheological properties. The addition of HGMs at the feeding zone closer to the die maintains the integrity of the hollow glass beads while promoting composites of improved mechanical properties and lower density when compared with the composites obtained by the addition of HGMs closer to the hopper. However, further efforts are needed to obtain a more accurate way of manufacturing light-weight polymer composites reinforced with HGM with high mechanical properties.

So, the present work aims at investigating the effects of incorporating HGM and powdery ABS together in a central 
extruder zone and evaluating if this addition contributes to maintain the integrity of the HGM filler during the extrusion process. The morphological, physical, mechanical, thermal and rheological properties of ABS/HGM composites were evaluated. On the other hand, the effect of the use of a high impact ABS modifier on the composite properties was also evaluated.

\section{Experimental}

\subsection{Materials}

ABS SV-0165 used as polymer matrix was supplied by Samsung Starex, China, with impact strength (ASTM D256-10) of $245 \mathrm{~J}^{-1}$. High impact ABS SD-0190H modifier was also supplied by Samsung Starex, China, with

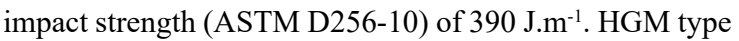
S038HS with no surface treatment were supplied by $3 \mathrm{M}^{\mathrm{TM}}$, Brazil, (Glass Bubbles ${ }^{\circledR}$ ). The HGM density is $0.38{\mathrm{~g} . \mathrm{cm}^{-3}}^{-3}$ while the compression strength is $34.5 \mathrm{MPa}$. The composite density was determined using ethanol PA (purity 99.9\%) supplied by Merck.

\subsection{Composite preparation}

ABS SV-165 and ABS SD-0190H were previously dried in a Marconi (Brazil) oven at $60{ }^{\circ} \mathrm{C}$ for $24 \mathrm{~h}$. Composites were prepared in a corotating and interpenetrating twin-screw extruder (MH Equipments/Brazil) with length/diameter(L/D) ratio of $32 \mathrm{~mm}$ and $20 \mathrm{~mm}$ screw with rotating speed 100 rpm and temperature profile $200-200-230-240{ }^{\circ} \mathrm{C}$.

HGMs were incorporated into an ABS matrix at the central extruder zone at percentages of 2.5, 5.0, and $7.5 \mathrm{wt} . \%$ along with 5 wt. $\%$ of ABS SV-165 using a side feeder (MH Equipments/Brazil) to evaluate if the incorporation of HGM together with ABS SV-165 improves the HGM distribution into the ABS matrix, as can be seen in Figure 1(a). In addition, a high impact ABS composite was also developed. The

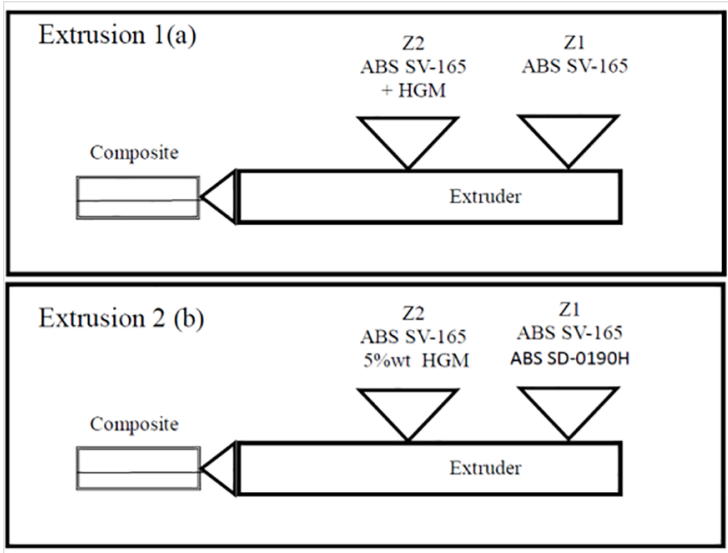

Figure 1. HGM incorporation at the central extruder zone with 5.0 wt. $\%$ of ABS (a); and incorporation of high impact ABS at the feeding zone (b). composite contains 45 wt. $\%$ of ABS SV- 165 and 45 wt. $\%$ of high impact ABS SD-0190H added at the extruder feeding section and 5 wt. $\%$ of HGM along with 5 wt. $\%$ of ABS SV165 incorporated at the central extruder zone using a side feeder (MH Equipments/Brazil) (Figure 1(b)). Compositions used in this study are listed in Table 1.

\subsection{Composite characterization}

Plates were produced by compression molding in the dimensions of $165 \times 95 \times 3 \mathrm{~mm}$ in a model 30010-4-1 (Brazil) press, at a pressure of 60 bar for 12 minutes, at 170 ${ }^{\circ} \mathrm{C}$ and cooled to $60^{\circ} \mathrm{C}$. Specimens for mechanical tests were obtained from plates cut using a band saw.

Morphological characterization was performed using a Shimadzu (Japan) scanning electron microscope (SEM). The specimens were frozen under liquid nitrogen, fractured, coated with gold and observed using an accelerating voltage of $15 \mathrm{kV}$.

Density was evaluated in accordance with the ASTM D4052-95 Method by the pycnometer method.

Heat deflection temperature (HDT) analysis was carried out in a Ceast Instrument (Brazil) using a deflection load of 1.8 MPa, in accordance with the ASTM D648-07 Method.

Rheological properties were analyzed in an Anton Paar Physica MCR 101 (USA) parallel plate oscillating rheometer in accordance with the ASTM D7395-07 Method, with frequency variation of 0.01 and $100 \mathrm{rad} . \mathrm{s}^{-1}$ and temperature from -180 to $200{ }^{\circ} \mathrm{C}$ under a nitrogen atmosphere, at a rate of $10{ }^{\circ} \mathrm{C} . \mathrm{min}^{-1}$, the test specimens having $20 \mathrm{~mm}$ diameter and $3 \mathrm{~mm}$ height.

Tensile strength was measured in accordance with ASTM D638-10 in an EMIC (Brazil) instrument model DL 2000, at a speed of $50 \mathrm{~mm} \cdot \mathrm{min}^{-1}$ with test specimens of $165 \times 13.3 \times 3 \mathrm{~mm}$ dimensions.

IZOD Impact strength was measured in accordance with ASTM D256-10 in a Ceast Resil equipment (Brazil) with a $4 \mathrm{~J}$ pendulum and $63 \times 12.7 \times 3 \mathrm{~mm}$ notch specimens. All test specimens' sides were sanded with 80 grain sand paper supplied by $3 \mathrm{M}^{\mathrm{TM}}$ do Brazil.

Statistical analysis (ANOVA) was performed using the Excel 2010 software. The parameters evaluated in the

Table 1. Codification and composition of the ABS and ABS/HGM composites.

\begin{tabular}{lc}
\hline Codification & Composition \\
\hline ABS/C & Z1:ABS control, 100 wt.\% ABS SV-165 \\
ABS/2.5 & Z1:92.5 wt.\% ABS SV-165 + Z2: 5.0 wt.\% \\
HGM/E1 & ABS SV-165 and 2.5 wt.\% HGM \\
ABS/5.0HGM/ & Z1:90 wt.\% ABS SV-165 + Z2: 5.0 wt.\% \\
E1 & ABS SV-165 and 5.0 wt.\% HGM \\
ABS/7.5HGM/ & Z1:87.5 wt.\% ABS SV-165 + Z2: 5.0 wt.\% \\
E1 & ABS SV-165 and + 7.5 wt.\% HGM \\
ABS/5.0HGM/ & $\begin{array}{l}\text { Z1:45 wt.\% of ABS SV-165 and 45 wt.\% of } \\
\text { high impact ABS SD-0190H + Z2: 5.0 wt.\% } \\
\text { E2 }\end{array}$ \\
& of HGM + 5.0 wt.\% of ABS SV-165 \\
\hline
\end{tabular}


statistical analysis included sum of squares (SQ), degrees of freedom (Gl), and mean squares (MQ). Values of $p<0.05$ were considered significant.

\section{Results and Discussion}

\subsection{Morphological properties}

SEM micrographs of the composites with 2.5, 5.0 and 7.5 wt.\% of HGM with 5.0 wt.\% of ABS SV-165 incorporated at the central extruder zone (Z2) are shown in Figure 2. It is possible to observe that some HGM were removed from the ABS matrix at the time of the fracture probably due to the low chemical affinity between reinforcement and matrix ${ }^{11}$. The ABS polarity is restricted to the acrylonitrile monomer, the remaining of its structure being of a nonpolar character, while HGM presents some polarity due to the hydroxyl groups at the microsphere surface. The interaction between matrix and reinforcement, if any, could be due to intermolecular attraction forces between the matrix acrylonitrile monomer and HGM hydroxyl groups.

It also can be seen in Figure 2 that almost all the HGM appeared to have withstood the compressive forces encountered during the extrusion process after being incorporated at the central extruder zone. The HGM are submitted to less shear forces when fed at this zone and therefore maintain their structure during the extrusion process. In our previous study $^{11}$, the HGM were incorporated at the extruder feeding point and the results showed that HGM were broken due to the higher residence time at the extruder associated with higher shear forces of the twin-screw extrusion process. The addition of ABS powder along with the HGM seems to promote better incorporation of the reinforcement by the polymer matrix, however, according to Figure 2(a) and Figure 2(c) the addition of $2.5 \mathrm{wt} . \%$ and $7.5 \mathrm{wt} . \%$ reinforcement promotes the agglomeration of the microspheres, while the addition of $5.0 \mathrm{wt} \% \%$ results in better filler dispersion in the polymer matrix as can be seen in Figure 2(b). The better filler dispersion with $5.0 \mathrm{wt}$ \% HGM probably occurs because the addition of the ABS SV-165 was also done in the same quantity $(5.0 \mathrm{wt} . \%)$ at the central extruder zone, which may promote better dispersion of the filler in the matrix, while the addition of 2.5 wt. $\%$ and $7.5 \mathrm{wt} \% \%$ of HGM generates filler agglomeration. The addition of 5.0 wt.\% HGM and 5.0 wt.\% of ABS powder at the same time at the central extruder zone promotes a synergistic effect in HGM dispersion, which was not observed for the $2.5 \mathrm{wt} . \%$ and 7.5 wt.\% HGM-containing composites.
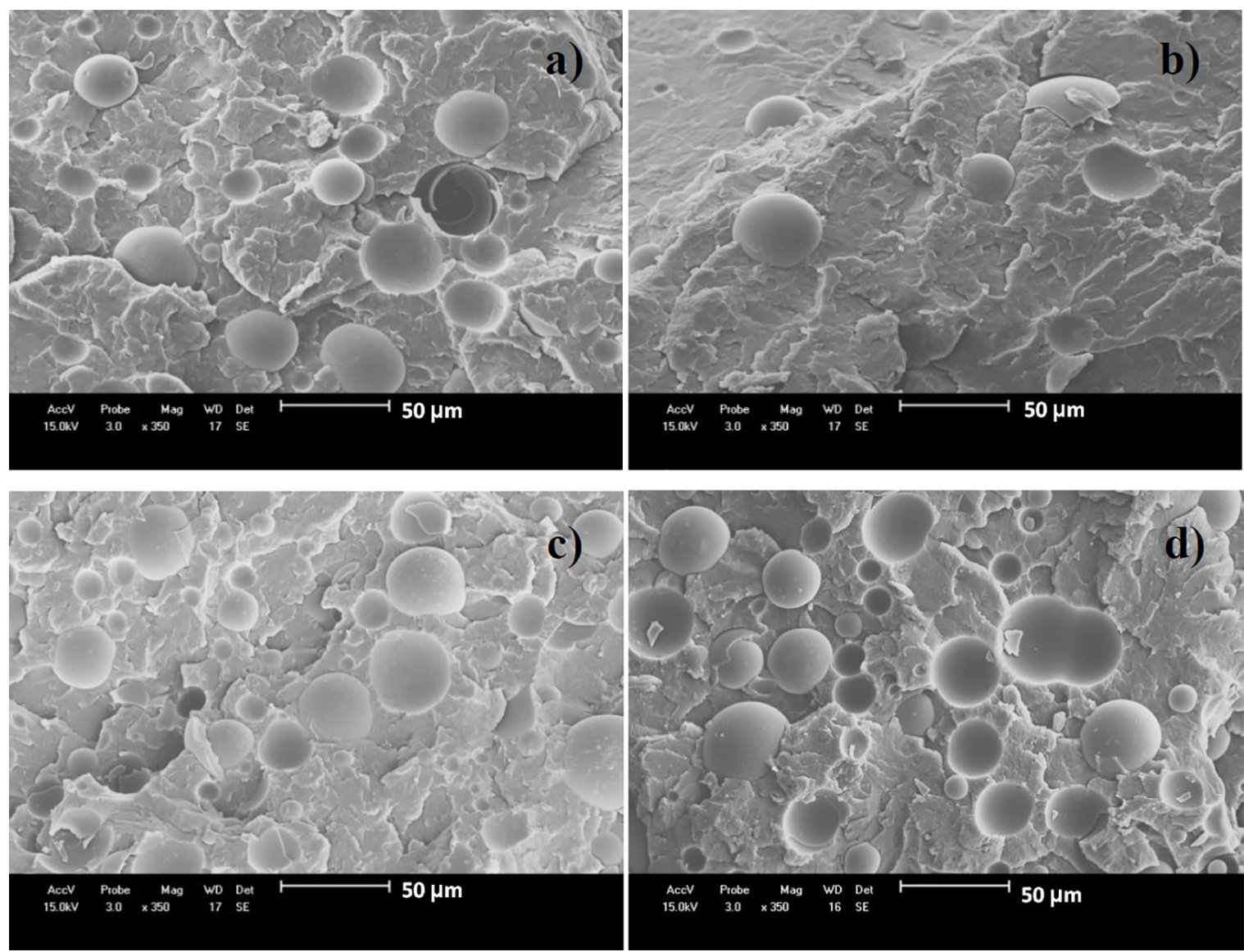

Figure 2. SEM micrographs of the composites with ABS/2.5 HGM/E1 (a), ABS/5.0 HGM/E1 (b), ABS/7.5 HGM/E1 (c) and ABS/5.0 HGM/E2 (d). 
The SEM micrograph of the composite with $5.0 \mathrm{wt} . \%$ of HGM and 45 wt.\% of high impact ABS is shown in Figure 2(d). HGMs were also removed from the ABS matrix due to the lower chemical affinity between matrix and reinforcement, as explained above. An agglomeration of the microspheres can also be seen in Figure 2(d).

\subsection{Density and HDT values}

Reduction a materials density, therefore its weight, without reducing its mechanical properties is one the main challenges of the automotive industries ${ }^{3,11}$. The density and HDT values of the composites studied are presented in Table 2. The addition of HGM reduced the density of all samples studied. It may be observed that the addition of $5.0 \mathrm{wt} . \%$ of HGM promotes a decrease of $12.5 \%$ in density, when compared with the matrix. This is first attributed to the added light-weight HGM which possess a density of $0.98 \mathrm{~g} . \mathrm{cm}^{-3}$. Adding the microspheres along with the ABS powder at the central extruder zone (Z2) also contributes to preserving the HGM integrity during compounding probably due to the better incorporation of the microspheres into the polymer matrix, however, no statistical differences were observed as can be seen in Table 2 .

The composites presented an increase in HDT with the addition of HGM when compared with the ABS matrix. The composite with 7.5 wt.\% of HGM showed the best result with an increase of $8 \%$ in HDT value, when compared with the $\mathrm{ABS} / \mathrm{C}$. According to Scaffaro et al. ${ }^{12}$ the increase in HDT values is attributed to the increase in composite stiffness, due to the presence of HGM, which therefore requires more energy for molecular mobility. On the other hand, the composite with high impact ABS exhibits a HDT value like the ABS matrix. This result may indicate that the higher quantity of butadiene present in the composite matrix with the addition of high impact ABS might have rendered the composite more ductile.

When compared with pure ABS, the density of all composites studied decreased while the thermal stability increased. These two properties are important for the automotive industry since ABS is one the most widely used polymers in this industry ${ }^{8}$.

\subsection{Rheological properties}

Dynamic rheological analysis can provide information on the evolution of the polymeric materials in the melt state, which can be used to anticipate the internal structures and processing properties of polymeric materials ${ }^{11,13}$. Storage modulus $\left(G^{\prime}\right)$ represents the elastic response of a material, which relates to the potential energy stored by the material during deformation. Hence, the value of $G^{\prime}$ can be used as a comparative estimative of the stiffness of the material ${ }^{13,14}$. Figure 3 represents the frequency dependence of the storage modulus ( $\left.G^{\prime}\right)$ for the ABS and ABS/HGM composites. It is apparent that the $G^{\prime}$ of the composites increases with the increase in HGM content. This result may be associated with the reinforced effect caused by the incorporation of the rigid $\mathrm{HGM}^{14}$. Furthermore, this result indicates that large-scale polymer relaxations are restrained by the presence of HGM

Table 2. Density and HDT of the composites as a function of HGM content with statistical analysis of the samples studied.

\begin{tabular}{|c|c|c|c|c|c|c|c|}
\hline \multirow{2}{*}{ Samples } & & \multicolumn{3}{|c|}{ Density } & \multicolumn{3}{|c|}{ HDT } \\
\hline & & \multicolumn{3}{|c|}{$\left(\mathrm{g} . c m^{-3}\right)$} & \multicolumn{3}{|c|}{$\left({ }^{\circ} \mathrm{C}\right)$} \\
\hline $\mathrm{ABS} / \mathrm{C}$ & & \multicolumn{3}{|c|}{$1.04 \pm 0.001$} & \multicolumn{3}{|c|}{$83.3 \pm 0.4$} \\
\hline $\mathrm{ABS} / 2.5 \mathrm{HGM} / \mathrm{E} 1$ & & \multicolumn{3}{|c|}{$0.99 \pm 0.001$} & \multicolumn{3}{|c|}{$87.2 \pm 0.2$} \\
\hline $\mathrm{ABS} / 5.0 \mathrm{HGM} / \mathrm{E} 1$ & & \multicolumn{3}{|c|}{$0.91 \pm 0.001$} & \multicolumn{3}{|c|}{$86.6 \pm 0.7$} \\
\hline $\mathrm{ABS} / 7.5 \mathrm{HGM} / \mathrm{E} 1$ & & \multicolumn{3}{|c|}{$1.02 \pm 0.001$} & \multicolumn{3}{|c|}{$89.7 \pm 0.8$} \\
\hline $\mathrm{ABS} / 5.0 \mathrm{HGM} / \mathrm{E} 2$ & & \multicolumn{3}{|c|}{$0.95 \pm 0.010$} & \multicolumn{3}{|c|}{$84.9 \pm 0.4$} \\
\hline \multicolumn{8}{|c|}{ ANOVA-Density } \\
\hline Source of variation & SQ & gl & MQ & $\mathbf{F}$ & P Value & F critical & Significant \\
\hline ABS SV-165 in Z2 & 0.007 & 5 & 0.001 & 0.0085 & 0.931 & 7.709 & No \\
\hline $\begin{array}{l}\text { HGM wt. } \% 2.5 \text { / } 5.0 \\
\text { / } 7.5\end{array}$ & 0.007 & 53 & 0.000015 & 0.7530 & 0.543 & 9.552 & No \\
\hline $\begin{array}{l}\text { Addition of } \\
\text { ABSSD-0190H }\end{array}$ & 0.009 & 3 & 0.00053 & 0.1259 & 0.757 & 18.513 & No \\
\hline \multicolumn{8}{|c|}{ ANOVA - HDT } \\
\hline Source of variation & SQ & gl & MQ & $\mathbf{F}$ & P Value & F critical & Significant \\
\hline ABS SV-165 in Z2 & 31.892 & 5 & 17.6470 & 4.9554 & 0.090 & 7.709 & No \\
\hline $\begin{array}{l}\text { HGM wt. } \% 2.5 \text { / } 5.0 \\
\text { / } 7.5\end{array}$ & 31.892 & 5 & 1.5930 & 0.1660 & 0.854 & 9.552 & No \\
\hline $\begin{array}{l}\text { Addition of ABSSD- } \\
0190 \mathrm{H}\end{array}$ & 6.655 & 5 & 0.8816 & 0.6108 & 0.478 & 7.709 & No \\
\hline
\end{tabular}




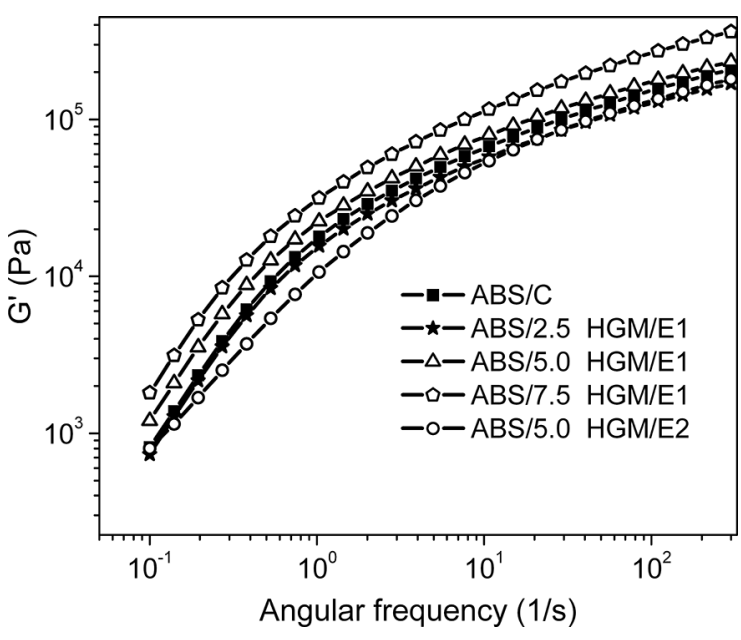

Figure 3. Storage modulus (G') versus angular frequency for composites with $2.5,5.0$ and $7.5 \mathrm{wt} . \%$ of HGM and composite with high impact $\mathrm{ABS}$.

effectively, which agrees with the HDT results. In addition, the incorporation of HGM improves the stiffness of ABS, which is consistent with the results obtained in other studies ${ }^{11,13,14}$. The storage modulus of the composite with high impact ABS was lower than that of the ABS/C polymer. This behavior can be attributed to the higher quantity of butadiene that can lead to a more ductile composite material.

The complex viscosity $\left(\eta^{*}\right)$ of $\mathrm{ABS} / \mathrm{C}$ and $\mathrm{ABS} / \mathrm{HGM}$ composites (ABS/2.5 HGM/E1, ABS/5.0 HGM/E1, ABS/7.5 $\mathrm{HGM} / \mathrm{E} 1$ and $\mathrm{ABS} / 5.0 \mathrm{HGM} / \mathrm{E} 2)$ as a function of angular frequency $(\omega)$ is shown in Figure 4. In the shear rate range studied, the complex viscosity of pure ABS and all the composites shows a shear thinning effect, which is ascribed to the reduction in entanglement density of ABS chains under the influence of high shear stress. Furthermore, the composites exhibit increased viscosity with the increase in HGM content. This phenomenon can be attributed to the interactions established between the polymer melt and the microscopically rough surface of the HGM surface.

Complex viscosity values indicate that the incorporation of HGM does not change the shear thinning behavior but affects the index of viscosity at a given shear rate. Similar results are found in other reports involving polymer based/ HGM composites ${ }^{13,14}$.

\subsection{Mechanical properties}

Table 3 presents the tensile strength and modulus of ABS/C and composites as a function of HGM content. Addition of $2.5 \mathrm{wt} . \% \mathrm{HGM}$ causes a slight decrease in the tensile strength value when compared with the polymer matrix, while the addition of $7.5 \mathrm{wt} . \%$ results in a more accentuated decrease in the composite tensile strength value. This behavior may be ascribed to HGM agglomeration previously observed in SEM analysis, which decreases the effectiveness of reinforcement. The $5.0 \mathrm{wt} . \%$ HGM composite had the highest tensile strength value, which might be associated with improved HGM dispersion into the polymer matrix, as observed in Figure 5. However, no statistically significant difference was observed in tensile strength as a function of HGM content. According to the literature, when the HGM are homogeneously dispersed in the polymer matrix they effectively act as reinforcement ${ }^{11,15-17}$. On the other hand, the composite with high impact ABS and 5.0 wt.\% HGM $(\mathrm{ABS} / 5.0 \mathrm{HGM} / \mathrm{E} 2)$ presents a decrease of $16 \%$ in tensile strength when compared with ABS/C. The ductile behavior promoted by the higher amounts of ABS butadiene associated with microspheres' agglomeration observed in Figure 2(d) may contribute to the decrease in tensile strength in this sample. In general, the modulus increases continuously with filler addition. The increase in modulus is also caused by the presence of the microspheres, which improves the stiffness of the composite ${ }^{18-20}$. Modulus enhancement with HGM loading corresponds well with the afore-mentioned storage modulus observed in dynamic rheological measurements.

Impact strength of the $\mathrm{ABS}$ and $\mathrm{ABS} / \mathrm{HGM}$ composites was also determined, as presented in Table 3 . The composites exhibit lower impact strength than neat ABS, which may be attributed to the fact that the HGM content brings brittleness to the formulations studied ${ }^{11,21}$. However, when the HGM content is equal to $5.0 \mathrm{wt} . \%$ the impact strengths of the ABS/ HGM composites is higher than those of any other composite formulations ( $2.5 \mathrm{wt} . \%$ and $7.5 \mathrm{wt} . \%$ of HGM). Thus, an increase in impact strength does not depend only on the improved interface adhesion between ABS and HGM but may depend on a complete stress transfer path that may be associated with better dispersion of the microspheres in the polymer matrix, which can promote better stress transfer to the matrix from the reinforcement microspheres. A similar result was also found in a report involving polymer-based/ HGM composites ${ }^{13}$. The composite containing high impact ABS shows the highest impact strength. The higher quantity

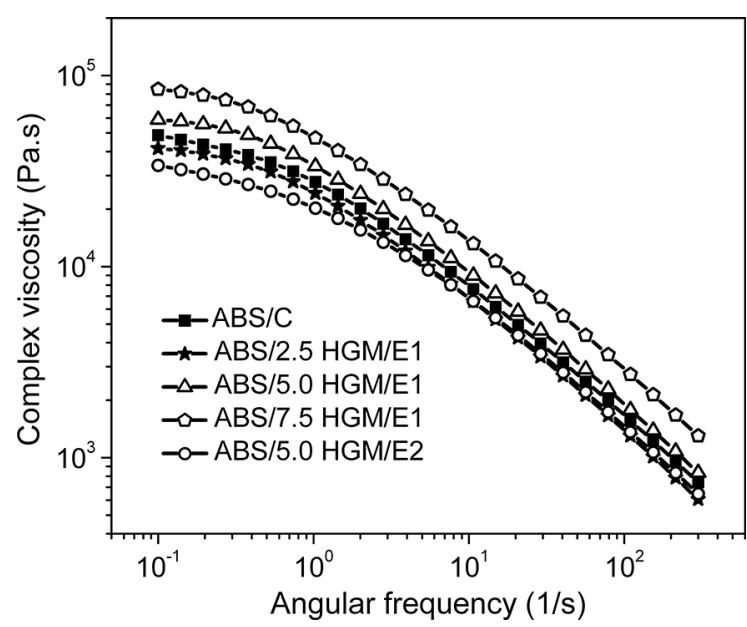

Figure 4. Complex viscosity $\left(\eta^{*}\right)$ versus angular frequency for composites with $2.5,5.0$ and 7.5 wt.\% of HGM and composite with high impact $\mathrm{ABS}$. 
Table 3. Mechanical properties of the composites as a function of HGM content with statistical analysis of the samples studied.

\begin{tabular}{lcccc}
\hline Samples & $\begin{array}{c}\text { Tensile strength } \\
(\mathrm{MPa})\end{array}$ & Tensile strain $(\%)$ & $\begin{array}{c}\text { Tensile modulus } \\
(\mathrm{MPa})\end{array}$ & Impact strength $(\mathrm{J} / \mathrm{m})$ \\
\hline $\mathrm{ABS} / \mathrm{C}$ & $22.73 \pm 0.96$ & $37.60 \pm 13.97$ & $509.90 \pm 36.18$ & $53.77 \pm 2.47$ \\
$\mathrm{ABS} / 2.5 \mathrm{HGM} / \mathrm{E} 1$ & $21.51 \pm 0.40$ & $34.00 \pm 7.13$ & $491.40 \pm 18.10$ & $39.88 \pm 2.78$ \\
$\mathrm{ABS} / 5.0 \mathrm{HGM} / \mathrm{E} 1$ & $22.90 \pm 0.70$ & $27.96 \pm 6.00$ & $498.40 \pm 20.10$ & $43.84 \pm 5.04$ \\
$\mathrm{ABS} / 7.5 \mathrm{HGM} / \mathrm{E} 1$ & $17.39 \pm 0.80$ & $8.04 \pm 2.94$ & $555.70 \pm 21.39$ & $19.54 \pm 1.54$ \\
$\mathrm{ABS} / 5.0 \mathrm{HGM} / \mathrm{E} 2$ & $19.01 \pm 0.78$ & $24.61 \pm 3.18$ & $554.80 \pm 42.73$ & $59.84 \pm 5.50$ \\
\hline
\end{tabular}

ANOVA - Tensile strength

\begin{tabular}{|c|c|c|c|c|c|c|c|}
\hline Source of variation & SQ & gl & MQ & $\mathbf{F}$ & $\begin{array}{c}P \\
\text { Value }\end{array}$ & F critical & Significant \\
\hline ABS SV-165 in Z2 & 29.995 & 5 & 4.369 & 0.682 & 0.455 & 7.709 & No \\
\hline HGM wt. $\% 2.5 / 5.0 / 7.5$ & 29.995 & 5 & 8.193 & 1.806 & 0.306 & 9.552 & No \\
\hline $\begin{array}{l}\text { Addition of ABS SD- } \\
0190 \mathrm{H}\end{array}$ & 20.882 & 3 & 3.297 & 0.380 & 0.602 & 18.513 & No \\
\hline
\end{tabular}

ANOVA - Impact strength

$\begin{array}{lccccccc}\text { Source of variation } & \text { SQ } & \text { gl } & \text { MQ } & \text { F } & \begin{array}{c}\text { P } \\ \text { Value }\end{array} & \text { F critical } & \text { Significant } \\ \text { ABS SV-165 in Z2 } & 517.986 & 5 & 14.372 & 0.114 & 0.752 & 7.709 & \text { No } \\ \text { HGM wt.\% 2.5/5.0/7.5 } & 517.986 & 5 & 159.642 & 2.410 & 0.238 & 9.552 & \text { No } \\ \begin{array}{l}\text { Addition of ABS SD- } \\ \text { 0190H }\end{array} & 518.800 & 3 & 271.600 & 18.510 & 0.027 & 2.197 & \text { Yes }\end{array}$

Sum of squares (SQ), degrees of freedom (Gl), and mean squares (MQ)

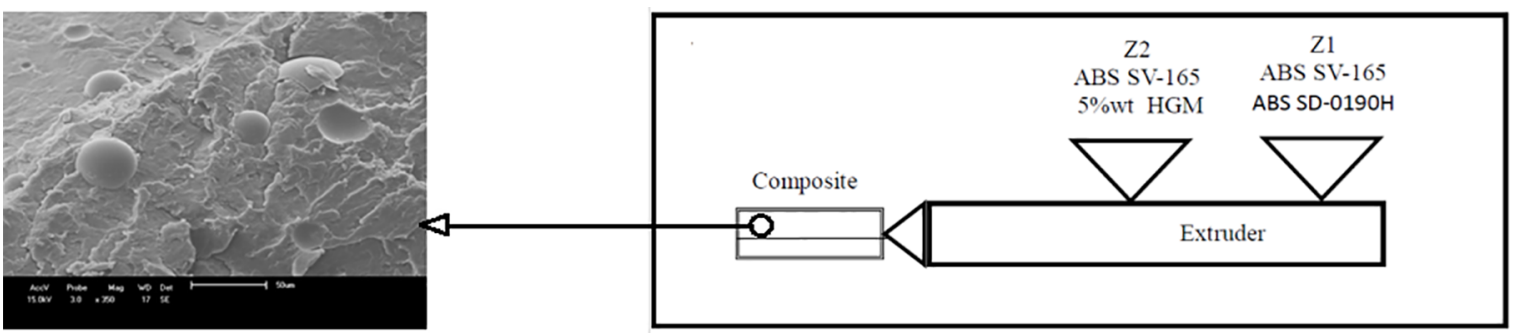

Figure 5. SEM micrograph of the composite with 5.0 wt.\% ABS SV-165 (Z2) and ABS SV-165 + ABS SD-0190H(Z1). Graphical Abstract.

of butadiene on the ABS SD- $0190 \mathrm{H}$ contributes to improve the composite impact strength. The impact strength of the high impact ABS composite is $11 \%$ higher than the polymer matrix. Statistical analysis reveals that the addition of high impact ABS is significant to improve the composite impact strength. In addition, the impact strength of the high impact ABS composite is $43 \%$ higher than the composite with 5.0 wt.\% HGM, which indicates that the high impact ABS added to the matrix contributes to the absorption of more energy during the impact test.

\section{Conclusion}

In this study, HGM-reinforced ABS composites have been prepared with the aid of a twin-screw extruder. Testing of morphological, physical, thermal, rheological and mechanical properties reveal that HGM plays an important role as reinforcement for improving the ABS stiffness and thermal properties. Moreover, the addition of HGM significantly reduced the composite density, with is desirable for industrial applications. The storage modulus, viscosity and HDT values of the composites were enhanced with the increase in HGM content. When the most important properties for composite applications are considered, such as density and mechanical properties, it was observed that adding HGM (5.0 wt.\%) at the central extruder zone together with $5.0 \mathrm{wt} . \%$ of powdery ABS showed the best results, probably because the integrity of the HGM was maintained and powdery ABS contributes to better filler dispersion into the matrix. This study shows that the properties of HGM-filled ABS matrix composites can be effectively controlled by adjusting the HGM/ABS powder feeding zone, ABS grade, and HGM content to develop light composites with higher mechanical performance that are potentially useful in the automotive industry. 


\section{Acknowledgments}

The authors are thankful to University of Caxias do Sul (UCS).

\section{References}

1. Patankar SN, Kranov YA. Hollow glass microsphere HDPE composites for low energy sustainability. Materials Science and Engineering: A. 2010;527(6):1361-1366.

2. Hu Y, Mei R, An Z, Zhang J. Silicon rubber/hollow glass microsphere composites: influence of broken hollow glass microsphere on mechanical and thermal insulation property. Composites Science and Technology. 2013;79:64-69.

3. Doumbia AS, Bourmaud A, Jouannet D, Falher T, Orange F, Retoux R, et al. Hollow microsphere - poly-(propylene) blends: relationship between microspheres degradation and composite properties. Polymer Degradation and Stability. 2015;114:146-153.

4. Kumar N, Mireja S, Khandelwal V, Arun B, Manik G. Light-weight high-strength hollow glass microspheres and bamboo fiber based hybrid polypropylene composite: A strength analysis and morphological study. Composites Part B: Engineering. 2017;109:277-285.

5. Gupta N, Ye R, Porfiri M. Comparison of tensile and compressive characteristics of vinyl ester/glass microballoon syntactic foams. Composites Part B: Engineering. 2010;41(3):236245 .

6. Tres PA. Hollow glass microspheres stronger spheres tackle injection molding. Plastics Technology. 2007;53:82-87.

7. Boldizar A, Möller K. Degradation of ABS during repeated processing and accelerated ageing. Polymer Degradation and Stability. 2003;81(2):359-366.

8. Liang JZ, Wu CB, Wei ZC. Correlation between impact strength and fracture surface fractal dimensions of ABS filled with hollow glass beads. Polymers for Advanced Technologies. 2012;23(1):108-113.

9. Delogu M, Zanchi L, Maltese S, Bonoli A, Pierini M. Environmental and economic life cycle assessment of a lightweight solution for an automotive component: a comparison between talc-filled and hollow glass microspheres-reinforced polymer composites. Journal of Cleaner Production. 2016;139:548-560.
10. Liang JZ. Mechanical Properties of Hollow Glass Bead-Filled ABS Composites. Journal of Thermoplastic Composite Materials. 2005;18(5):407-416.

11. Cunha MP, Gonella LB, Poletto M, Grisa AMC, Brandalise RN. Poly(acrylonitrile-co-butadiene-co-styrene) Reinforced with Hollow Glass Microspheres: Evaluation of Extrusion Parameters and Their Effects on the Composite Properties. Journal of Polymers. 2016;2016:9063874.

12. Scaffaro R, Botta L, Di Benedetto G. Physical properties of virginrecycled ABS blends: Effect of post-consumer content and of reprocessing cycles. European Polymer Journal. 2012;48(3):637648 .

13. Li J, Luo X, Lin X. Preparation and characterization of hollow glass microspheres reinforced poly(butylene succinate) composites. Materials \& Design. 2013;46:902-909.

14. Lu X, Qu J, Huang J. Mechanical, thermal and rheological properties of hollow glass microspheres filled thermoplastic polyurethane composites blended by normal vane extruder. Plastic, Rubber and Composites. 2015;44(8):306-313.

15. Jo MY, Ryu YJ, Ko JH, Yoon JS. Effects of compatibilizers on the mechanical properties of ABS/PLA composites. Journal of Applied Polymer Science. 2012;125(S2):E231-E238.

16. Im H, Roh SC, Kim CK. Fabrication of Novel Polyurethane Elastomer Composites Containing Hollow Glass Microspheres and Their Underwater Applications. Industrial \& Engineering Chemistry Research. 2011;50(12):7305-7312.

17. Liang JZ. Tensile and Flexural Properties of Hollow Glass BeadFilled ABS Composites. Journal of Elastomers and Plastics. 2005;37(4):361-370.

18. Zhu B, Ma J, Wang J, Wu J, Peng D. Thermal, dielectric and compressive properties of hollow glass microsphere filled epoxymatrix composites. Journal of Reinforced Plastics and Composites. 2012;31(19):1311-1326.

19. Tagliavia G, Porfiri M, Gupta N. Analysis of flexural properties of hollow-particle filled composites. Composites Part B: Engineering. 2010;41(1):86-93.

20. Jiang L, Lam YC, Tam KC, Chua TH, Sim GW, Ang LS. Strengthening acrylonitrile-butadiene-styrene (ABS) with nano-sized and micronsized calcium carbonate. Polymer. 2005;46(1):243-252.

21. Hornsby PR, Premphet K. Influence of phase microstructure on the mechanical properties of ternary phase polypropylene composites. Journal of Applied Polymer Science. 1998;70(3):587-597. 